\title{
PSYCHOLOGICAL CONTRACT VIOLATION AND THE ESCALATING CYCLE OF MISTRUST
}

\author{
Juliana D. Lilly \\ Sam Houston State University • Huntsville, TX
}

\section{ABSTRACT}

Psychological contract violations in the workplace can lead to disruptive behavior, but few studies have examined why the disruptive behavior may persist over time. This paper extends the current understanding of psychological contracts by proposing a model that illustrates an escalating cycle of mistrust resulting from a perceived contract violation. The model proposes that after a psychological contract violation has occurred, an escalating cycle of mistrust is created that feeds on itself through transactional cost behaviors of both the victim and the perpetrator of the violation. Once the cycle of mistrust has begun, it can only be broken if one party exhibits specific behaviors that focus on resolving the issue rather than perpetuating the cycle.

Keywords: psychological contract, trust, procedural justice

\section{INTRODUCTION}

When individuals experience disappointment or anger due to an unexpected occurrence, their reactions may vary from mild irritation that quickly dissipates to severe behavioral reactions that consume much time and effort. Consider the difference in a work disagreement over a routine report which is quickly forgotten versus a work disagreement over a routine report which turns into a long-term feud between coworkers or departments. All employees have good days and bad days, but why do individuals sometimes continue a fight long after the initial disagreement? And why does the disagreement spill into other areas not impacted by the original report in question? This paper attempts to answer these questions by presenting the escalating cycle of mistrust, a cycle originating from an incident, or series of incidents, that create disappointment or anger due to an unexpected occurrence.

Management researchers have examined behavioral issues in the workplace for decades, and studies on trust, organizational justice, and leadership have provided some insight into the psychology of work behavior. This research is important since work is a social endeavor, managers and employees are required to interact with one another, and disagreements may lead to disruptive behavior that interferes with organizational effectiveness. As such, studies that examine work disagreements 
and the subsequent anger or disappointment could be beneficial in finding ways to alleviate some of the resulting detrimental behaviors. The literature on psychological contracts in the workplace often includes elements of trust, organizational justice, and leadership in empirical studies of psychological contract violations and this research may help explain the psychological impulse to prolong a workplace disagreement.

A psychological contract is based on the concept of reciprocity between employees and organizations such that an employee who is loyal and productive expects the organization to reciprocate by treating the employee fairly in terms of pay and work conditions. Articles on corporate layoffs have alluded to the psychological contract when reporting on companies that terminated thousands of loyal, productive employees while executives profited (Brookman, Chang \& Rennie, 2007; Cramer, 1996; Maremont, 2005), a clear violation of the expectation of reciprocity between employees and organizations. One study found that psychological contract violations experienced by layoff victims from a previous employer were negatively related to trust in their new employer (Pugh, Skarlicki Passell, 2003), suggesting the emotional impact of the violation may be long-term and transferable to a neutral party. Other findings suggest that violations of the psychological contract could result in increased turnover (Arasli, et al., 2019; von Stormbroek \& Blomme, 2017), increased absenteeism (Deery, Iverson \& Walsh, 2006), lowered trust (Deery, Iverson \& Walsh, 2006; Kingshott \& Pecotich, 2007), and increased job neglect (Lo $\&$ Aryee, 2003). Although the two parties in a traditional psychological contract are considered to be the "employee" and the "organization," there are many individuals who could be perceived by the employee as representing the organization by proxy, such as supervisors, executives, and even coworkers. Thus, these individual proxies could trigger psychological contract violations that result in negative outcomes to the overall organization such as turnover, increased absenteeism, and job neglect.

The purpose of this paper is to extend the current understanding of psychological contract violations by proposing a model that illustrates an escalating cycle of mistrust that results from a perceived contract violation. The model is based on findings from the literature on psychological contracts, trust, and procedural justice. Research on trust in organizations has shown a relationship between perceived trust and organizational outcomes such as turnover (Zeffane \& Bani Melhem, 2017), performance (Verburg, et al., 2018)), and employee behavior (Duffy \& Lilly, 2013). Few studies, however, have considered trust in a longitudinal sense to study the long-term effect of mistrust on employee behaviors, and no studies to date have examined the potentially escalating cycle of mistrust in the workplace. This paper presents a model in which mistrust has already occurred due to a psychological 
contract violation and then examines the behavioral reactions of the two parties involved in the psychological contract. The resulting model depicts an escalating cycle of mistrust that can only be broken by specific behaviors focused on breaking the cycle.

\section{LITERATURE REVIEW}

\section{Psychological Contracts}

The term psychological contract typically refers to the expectations or beliefs held by employees concerning the reciprocal obligations between them and their organization (Morrison \& Robinson, 1997), but can also apply to customer-provider relationships (Rousseau, 1995; Rousseau \& Wade-Benzoni, 1994). In essence, a psychological contract is grounded upon expectations that one party has toward another. These expectations are not written or implied contracts; rather, they are perceptions of a socially constructed relationship (Robinson, Kraatz \& Rousseau, 1994). When these socially constructed relationships are not fully understood by both parties, misunderstandings may lead to a perceived contract violation.

Two types of psychological contracts identified in the literature are the transactional contract and the relational contract. A transactional contract is one in which an exchange of some sort takes place (Rousseau \& MacLean-Parks, 1993). For example, in a typical employee-employer relationship, the employer pays a fair wage to the employee in exchange for an appropriate level of productivity. A second form of contract, the relational contract, is characterized as a long-term contract that is not restricted to economic exchange (Morrison \& Robinson, 1997). Rather, the contract is somewhat broad and includes long-term emotional involvement as well as financial rewards. For example, one might assume long-term employee loyalty is a factor that could be exchanged for job security or job advancement in an organization. A study by Boey \& Vantilborgh (2015) found that personality characteristics help predict perceptions of psychological contract type as either transactional or relational.

Two factors that often act as antecedents to a psychological contract violation are incongruence and reneging (Morrison \& Robinson, 1997). Incongruence refers to a situation when the parties in a relationship have different expectations, and a misunderstanding occurs. As a result, one party believes the other has not fulfilled their obligations, while the other party believes they have fulfilled their obligations. This could occur when an employee who demonstrates exceptional work performance 
expects to receive recognition or a reward beyond what is normally received, but the organization does nothing out of the ordinary to recognize the performance, perhaps believing the salary and job security are sufficient to expect exceptional performance from employees. Reneging occurs when one party knowingly fails to fulfill their obligations, either because they do not want to or because they cannot. This type of violation could occur when an employee reaches a specified performance goal expecting a bonus, but the organization changes the bonus plan when too many employees successfully meet the goal.

Robinson and Morrison (2000) studied the antecedents of psychological contract violations and found that when an organization's performance had fallen short of what was expected, or when the employee's job performance was low, perceived contract violations by employees were more likely to occur. Concerning antecedents of incongruence, specifically, researchers found that psychological contract violations were less likely to occur when formal socialization and prehire interaction between employees and the employing organization had occurred (Robinson \& Morrison, 2000; Woodrow \& Guest, 2020). This seems likely since formal socialization and onboarding processes often clearly outline expectations of behavior and performance in the organization.

A number of studies have examined the longitudinal aspects of psychological contracts (e.g., Freese, Schalk \& Croon, 2011; Lester, Kickul \& Bergmann, 2007; Woodrow \& Guest, 2020), and the longitudinal study of psychological contracts is particularly interesting since the very nature of the contract in a work setting tends to be a long-term endeavor. However, to fully understand employee reactions in any work setting, individual characteristics and behaviors must also be considered. Thus, this paper proposes to develop a long-term view of the psychological contract, but only after a contract violation has occurred. As with any disappointing experience, the individual experiencing the disappointment may engage in behaviors that are hurtful to themselves as well as others. This is no different in a workplace setting, such that disappointment due to a psychological contract violation may be very damaging or disruptive to the work environment. Indeed, perceived injustice at work (a disappointing outcome) has been linked to deviant behavior in multiple studies (e.g., Priesemuth, Arnaud \& Schminke, 2013; Zoghbi-Manrique-de-Lara , 2010). Although the preferred course of action is to prevent a violation from ever occurring in the first place, inevitably, a violation will occur, and the focus should be on how to fix the situation. The model presented in this paper thus focuses on the aftermath of a violation and behaviors to ameliorate the negative impact. 


\section{Trust}

Trust is defined as employees' willingness to be vulnerable to the actions of their employer based on positive expectations about its intentions or behavior (Mayer, et al., 1995). The initial reaction to a psychological contract violation is often a decrease in trust (Deery, Iverson \& Walsh, 2006; Robinson, 1996). Trust has become a major topic of research in the social science literature because trust is recognized as an important aspect of maintaining cooperation in long-term relationships (Tyler \& Kramer, 1996). Violations of trust are similar to violations of psychological contracts in that expectations are unmet (Anderson \& Narus, 1990; Lewis \& Weigert, 1985) and values of the parties are incongruent (Sitkin \& Roth, 1993). When trust in a relationship is low or nonexistent, the parties may insist on costly sanctioning mechanisms to protect themselves, a type of trust known as calculus-based trust (Lewicki \& Bunker, 1996). In calculus-based trust, the threat of punishment is the mechanism by which cooperation is ensured, and the parties may spend enormous amounts of time and money monitoring each other to ensure each is adhering to their commitments. These monitoring behaviors are actually the transactional costs of maintaining the relationship, in that the two parties must spend time, effort, and money to ensure their interests are protected. Calculus-based trust is the lowest level of trust and is often associated with new relationships or relationships that have never grown beyond the first stage of trust.

Two higher stages of trust, knowledge-based trust and identification-based trust, focus on regular communication plus an understanding and appreciation for the other party in a relationship (Lewicki \& Bunker, 1996). At these levels of trust, the parties are often willing to forgive the other for transgressions in behavior because the two parties understand that they share common values and objectives. Trust at these higher levels helps remove some of the costly compliance mechanisms present in calculus-based trust. Thus, repairing the damage from a psychological contract violation requires both parties to recognize the importance of nurturing trust in the relationship.

\section{Procedural Justice}

Procedural justice refers to the fairness of a decision-making procedures leading to a decision outcome (Lilly, 2016). Procedural justice research has focused primarily on the idea that individuals desire some amount of control over decisions that affect them (Thibaut \& Walker, 1975), and many studies have researched the effects of procedural justice in organizations concerning issues such as layoff 
decisions and performance appraisals (see Brockner \& Weisenfeld, 1996, for a review). When individuals believe they have some control over the process used to make decisions, they are more likely to say the final outcome is fair even if the outcome is unfavorable to them (Thibaut \& Walker, 1975). Some basic components of procedural justice include the ability to have input into the final decision, the ability to appeal a bad decision, consistency in implementing the decision process, and lack of bias on the part of the decision-maker (Leventhal, 1980).

The academic literature on procedural justice and trust is vast and very rich in examining the impact of these constructs in organizations. In the present paper, however, procedural justice and trust are considered somewhat basic in a relationship context since the two constructs are defined in a similar way to what one would see in a dictionary. For example, a performance evaluation system is perceived by employees to be either a fair process or an unfair process based on normative expectations of what an evaluation system should be. Likewise, an organization is perceived by employees as either trustworthy or untrustworthy based on normative expectations of how an organization should treat employees and other stakeholders. Psychological contracts, however, are a little more complicated. The relationship between the parties of interest in a psychological contract is often more complex since the expectations in a psychological contract are more likely to be unknown, ambiguous, or misinterpreted. Misinterpretation of another party's behavior or not knowing the cause of another party's behavior often leads to a lack of trust between the two parties. Thus, this study attempts to determine how psychological contract violations, trust, and procedural justice are related to one another, and how behaviors resulting from mistrust may increase the level of mistrust over time.

\section{Perpetrators And Victims}

In a psychological contract violation, the perpetrator is the party who violates the contract while the victim is the party who suffers from the violation. The perpetrator has some control over the victim's response even if the perpetrator is initially unaware of the violation. For example, when the victim responds in anger to a psychological contract violation by engaging in disruptive work behavior, the perpetrator becomes fully aware at that time the victim is upset. At this point, how the perpetrator responds should influence the victim's subsequent response, and research on workplace revenge suggests the victim may choose to forgive a perpetrator under certain situations (Bies \& Tripp, 1996). For example, the victim may allow the perpetrator to redeem himself or herself if the victim believes the 
perpetrator is empathetic to their situation or if the victim believes the perpetrator is willing to change their behavior to correct the violation (Bies \& Tripp, 1996). In addition, the victim may forgive the perpetrator if the victim believes the perpetrator is focused on the situation and how to solve the problem rather than focused on the individual personalities involved in the situation (Heider, 1958).

The most preferable means of dealing with dissatisfaction in any relationship is to prevent it from ever occurring in the first place. Unfortunately, in some situations, the violation has already occurred and both the perpetrator and victim are forced to deal with the effects of the violation. Based on the idea that violations occur despite good efforts to prevent them, a model depicting the outcomes of psychological contract violation was developed as shown in Figure 1.

Figure 1

The Escalating Cycle of Mistrust

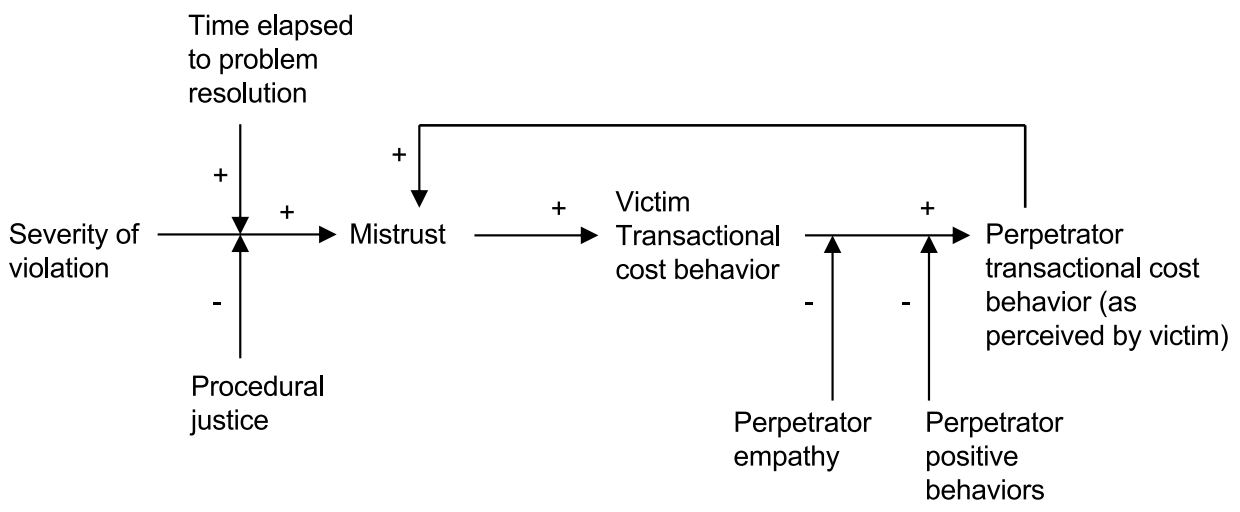

\section{THE MODEL AND PROPOSITIONS}

The model presented in Figure 1 identifies severity of psychological contract violation as the starting point of interest. After the psychological contract violation has occurred, the model depicts a continuous cycle of mistrust that feeds on itself through transactional cost behaviors of both the victim and the perpetrator. The cycle of mistrust can be reduced initially through the use of timely and fair procedures that correct unmet expectations. As the victim's level of mistrust increases, however, perhaps because there are no procedures in place to resolve differences or because procedures in place are not used properly, the victim begins to engage in transactional cost behaviors to protect their interests in the relationship. If the 
perpetrator is perceived by the victim to also increase their transactional cost behaviors in response, the level of mistrust is again increased, causing the victim to once again increase their transactional cost behaviors, thus feeding the cycle of mistrust on a continuous basis. Once the cycle of mistrust has begun, it can only be broken if one party exhibits specific behaviors that focus on resolving the issue rather than focusing on "beating" the other party.

It has been empirically established that once a perceived violation has occurred, a reduction of trust in the other party leads to subsequent reactions that are detrimental to the organization (Robinson, 1996). In an employment relationship these reactions may include a reduction in job performance (Lo \& Aryee, 2003), organizational citizenship behavior (Arshad \& Sparrow, 2010), and increased turnover (Asrali, et al., 2019). A perceived psychological contract violation should also result in subsequent reactions that are detrimental to the ongoing relationship. Such negative reactions may include harsh criticism of either or both parties, perhaps even public criticism, or resorting to legal procedures in settling the disagreement. As such, proposition 1 serves as a test of the relationship between severity of contract violation and mistrust in the customer-provider relationship, while proposition 2 serves as a test of the relationship between trust and victim transactional cost behaviors.

Proposition 1: There is a positive relationship between the severity of the psychological contract violation and mistrust.

Proposition 2: There is a positive relationship between mistrust and victim transactional cost behaviors.

Mistrust in this situation acts as a mediator between severity of violation and victim transactional cost behaviors. This premise is supported by theory on psychological contract violation that suggests a contract breach (i.e. a cognition that expectations are unmet) is followed by a contract violation (i.e. an emotional response to the breach) (Morrison \& Robinson, 1997; Robinson \& Morrison, 2000), which then results in behavioral responses to the violation (Robinson, 1996). In support of this premise, Agarwal (2014) found that trust positively mediated the relationship between psychological contract fulfilment and work engagement, with engagement significantly influencing employee innovative work behavior. Therefore, proposition 3 outlines the mediating effect of mistrust on the relationship between severity of contract violation and negative behavioral outcomes. 
Proposition 3: There is a mediating effect of mistrust on the relationship between severity of psychological contract violation and victim transactional cost behaviors.

Procedural justice research has focused on whether or not fair procedures lead to greater acceptance of an unfavorable outcome (Thibaut \& Walker, 1975). It is possible to have a process that is fair in theory, but not in practice; therefore, procedural justice issues should be carefully considered from all perspectives before making decisions on how the process is created and implemented. Nevertheless, studies have shown that when procedures allow the individual to maintain some control over the final outcome, the process is considered to be more fair than if no control over the process and outcome are present (e.g., Greenberg, 1986). Therefore, the presence of procedural justice should lessen the negative effect of mistrust that occurs after a contract violation, leading to the following proposition:

Proposition 4: There is a negative moderating effect of procedural justice on the relationship between severity of violation and mistrust.

American citizens are guaranteed by law the right to a fair and speedy trial when accused of wrongdoing under the general principle that justice delayed is justice denied. In fact, researchers have found that temporal urgency in disputes affects the disputants' preferred method of conflict resolution (Thibaut \& Walker, 1975). As such, the timing of a process used to solve a dispute becomes important, with longer time lapses between the start of a conflict to the resolution of the conflict most likely to create increased feelings of mistrust.

Proposition 5: There is a positive moderating effect of length of time elapsed to problem resolution on the relationship between severity of violation and mistrust.

In one study of trust, subjects were asked to name the person who has made it the most difficult for them to carry out their job responsibilities. When asked to explain why they named that particular person, the explanations indicated that the person was uncooperative (Burt \& Knez, 1996). If the victim of a psychological contract violation believes the perpetrator is uncooperative, he or she is likely to perceive the perpetrator as someone who will be uncooperative or retaliate when the victim acts to protect their interests using transactional cost behaviors. Even if the perpetrator does not retaliate, the victim may perceive any neutral action as an attempt to hurt the victim's ability to monitor the relationship due to an egocentric bias in 
the experience of pain by victims (Bies \& Tripp, 1996). In fact, the fundamental attribution error (Ross, 1977) suggests that individuals are more likely to blame the person for any undesirable behavior rather than the situation. Thus, individuals who experience an unfavorable experience of any kind are more likely to blame the perpetrator for all actions connected to the experience than to blame factors external to the perpetrator. In addition, if the victim is likely to blame the perpetrator for all actions connected to the experience, the victim is also likely to increase the level of mistrust directed toward the perpetrator. Propositions 6 and 7 depict these relationships.

Proposition 6: There is a positive relationship between victim transactional cost behavior and perpetrator transactional cost behavior as perceived by the victim.

Proposition 7: There is a positive relationship between perpetrator transactional cost behavior as perceived by the victim and mistrust.

Specific behaviors exhibited by the perpetrators may help reduce the victim's perception of retaliation. For instance, Bies \& Tripp (1996) found that when victims believed a trust violation was caused by factors beyond the perpetrator's control, victims tended to forego revenge tactics. However, if the perpetrator offered no explanation or apology for their actions, victims were more motivated to take revenge. These findings are in line with attribution theory (Heider, 1958) in which individuals make either dispositional or situational attributions for the behavior of others. Specific perpetrator behaviors that indicate empathy and a focus on solving the problem rather than defending the decision, or a recognition that behavior changes need to be made should ameliorate the victim's perception of retaliation by the perpetrator.

Proposition 8: Perpetrator empathy will have a neutralizing moderating effect on the relationship between victim transactional cost behavior and transactional cost behavior of perpetrator as perceived by victim.

Proposition 9: Perpetrator positive behavior will have a neutralizing moderating effect on the relationship between victim transactional cost behavior and transactional cost behavior of perpetrator as perceived by victim.

It is clear from the model presented that the perpetrator has the primary 
responsibility to break the cycle of mistrust once it starts, even if the perpetrator does not perceive himself or herself as having committed a psychological contract violation. Although this may seem unfair, it is important to remember the model is developed from the victim's perspective, and the victim believes a wrong has occurred. This situation is not unlike a scenario in which one employee unintentionally offends a coworker. Once the offending employee knows how the coworker feels, the employee often apologizes even though the employee may believe he or she did nothing wrong. He apologizes nevertheless because the work relationship is more important than proving who was right. In essence, common courtesy and concern for another person's feelings help resolve an issue that could escalate over time. The model serves to illustrate how this escalation could occur without specific actions to stop the escalating cycle.

\section{PRACTICAL IMPLICATIONS AND FUTURE DIRECTIONS}

The model presented in the current paper is based on a workplace relationship typically considered when psychological contracts are discussed. However, the model, if supported, could be generalized to a number of different contexts, such as studying the relationships between business organizations and their customers, married couples, and even relationships between political parties or countries. The escalating cycle of mistrust may be too simplistic in its present form to fully explain the role of numerous personality traits, cultural styles, ethical values, and other individual characteristics inherent in relationships, but the basic model presents a starting point for understanding the need to break the cycle of mistrust before too much damage occurs.

Future research should consider introducing into the model some of the variables suggested above such as personality and culture, but another potentially interesting variable to include into the model is propensity to forgive. Individuals who are more likely to forgive might be less likely to increase their mistrust of the perpetrator. In other words, the victim might never instigate the cycle of mistrust if the victim has a high level of propensity to forgive others. Although the model is directed toward the victim's perspective, the perceived power level of the perpetrator might also be a factor. For instance, if the perpetrator is perceived as having high levels of reward or coercive power, the victim might not engage in the cycle of mistrust out of fear of the perpetrator. 


\section{CONCLUSION}

Many organizational behavior researchers focus on how to manage individual behavior in the workplace. To manage behavior, it is often necessary to understand why the behavior occurs in the first place; thus, the effort to explain why negative behavior may escalate over time in the workplace may help managers in their daily supervising activities. Basic courtesy and consideration of others is prevalent in the proposed model, and these concepts are tested by variables such as procedural justice, perpetrator empathy, and perpetrator positive behaviors. If the model is supported in subsequent empirical research, it will potentially help individuals in the workplace recognize the escalating cycle and help them engage in specific actions to stop it. Since workplace harmony and cooperation are often necessary to gain high levels of efficiency and productivity, any research that helps explain mistrust and negative workplace behaviors would be beneficial.

\section{REFERENCES}

Agarwal, U.A. (2014). Linking justice trust and innovative work behaviour to work engagement. Personnel Review, 43(1): 41-73.

Anderson, J. C. \& Narus, J. A. (1990). A model of distributor firm and manufacturer firm working partnerships. Journal of Marketing, 54(1): 42-58.

Arasli, H., Arici, H., Cakmakoğlu Arici, N. (2019). Workplace favouritism, psychological contract violation and turnover intention: Moderating roles of authentic leadership and job insecurity climate. German Journal of Human Resource Management, 33(3): 197-222.

Arshad, R. \& Sparrow, P. (2010). Downsizing and survivor reactions in Malaysia: Modelling antecedents and outcomes of psychological contract violation. The International Journal of Human Resource Management, 21(11): 1793-1815.

Bies, R. J. \& Tripp, T.M. (1996). Beyond distrust: "Getting even" and the need for revenge. In R. M. Kramer \& T. R. Tyler (Eds.), Trust in Organizations, pp. 246260. Thousand Oaks, CA: Sage.

Boey, L. \& Vantilborgh, T. (2015). A theoretical model relating the dark triad of personality to the content of employees' psychological contracts. New Zealand Journal of Employment Relations, 40(3): 44-66.

Brockner, J. \& Weisenfeld, B. M. (1996). An integrative framework for explaining reactions to decisions: Interactive effects of outcomes and procedures. Psychological Bulletin, 120: 189-208. 
Brookman, J. T., Chang, S. \& Rennie, C. G. (2007). CEO equity portfolio incentives and layoff decisions. Journal of Financial Research, 30(2): 259-281.

Burt, R. S. \& Knez, M. (1996). Trust and third-party gossip. In R. M. Kramer \& T. R. Tyler (Eds.), Trust in Organizations, pp. 68-89. Thousand Oaks, CA: Sage.

Cramer, J. (1996). Let them eat stocks. New Republic, 214(18): 24-25.

Deery, S. J., Iverson, R. D. \& Walsh, J. T. (2006). Toward a better understanding of psychological contract breach: A study of customer service employees. Journal of Applied Psychology, 91(1): 166-175.

Duffy, J. \& Lilly, J. D. 2013. Do individual needs moderate the relationship between $\mathrm{OCB}$, organizational trust, and POS? Journal of Behavioral and Applied Management, 14(3): 185-197.

Freese, C., Schalk, R. \& Croon, M. (2011). The impact of organizational changes on psychological contracts: A longitudinal study. Personnel Review, 40(4): 404422.

Greenberg, J. (1986). Determinants of perceived fairness of performance evaluations. Journal of Applied Psychology, 71: 340-342.

Heider, F. (1958). The Psychology of Interpersonal Relations. New York: John Wiley.

Kingshott, R. P. J. \& Pecotich, A. (2007). The impact of psychological contracts on trust and commitment in supplier-distributor relationships. European Journal of Marketing, 41(9/10): 1053-1072.

Lester, S. W., Kickul, J. R. \& Bergmann, T. J. (2007). Managing employee perceptions of the psychological contract over time: The role of employer social accounts and contract fulfillment. Journal of Organizational Behavior, 28: 191-208.

Leventhal, G. S. (1980). What should be done with equity theory? New approaches to the study of fairness in social relationships. In K. Gergen, M. Greenberg \& R. Willis (Eds.), Social Exchange: Advances in Theory and Research, pp. 27-55. New York: Plenum Press.

Lewicki, R. J. \& Bunker, B. B. (1996). Developing and maintaining trust in work relationships. In R. M. Kramer \& T. R. Tyler (Eds.), Trust in Organizations, pp. 114-139. Thousand Oaks, CA: Sage.

Lewis, J. D. \& Weigert, A. (1985). Trust as a social reality. Social Forces, 63(4): 967-985.

Lilly, J.D. 2016. Organizational justice. In A. Farazmand (ed.) Global Encyclopedia of Public Administration, Public Policy, and Governance (pp. 1-7). Switzerland: Springer International Publishing. http://link.springer.com/ referenceworkentry/10.1007/978-3-319-31816-5_2472-1 
Lo, S. \& Aryee, S. (2003). Psychological contract breach in a Chinese context: An integrative approach. Journal of Management Studies, 40(4): 1005-1020.

Maremont, M. (2005). No razor here: Gillette chief to get a giant payday -About $\$ 153$ million awaits Kilts after P \& G deal, his second merger score. The Wall Street Journal (Jan 31 2005).

Mayer, R.C., David, J. H. \& Schoorman, F. D. (1995). An integrative model of organizational trust. Academy of Management Review, 20, 709-734.

Morrison, E. W. \& Robinson, S. L. (1997). When employees feel betrayed: A model of how psychological contract violation develops. Academy of Management Review, 22(1): 226-256.

Priesemuth, M., Arnaud, A. \& Schminke, M. (2013). Bad behavior in groups: The impact of overall justice climate and functional dependence on counterproductive work behavior in work units. Group \& Organization Management, 38(2): 230257.

Pugh, S. D., Skarlicki, D. P. \& Passell, B. S. (20030. After the fall: Layoff victims'trust and cynicism in re-employment. Journal of Occupational and Organizational Psychology, 76: 201-212.

Robinson, S. L. (1996). Trust and breach of the psychological contract. Administrative Science Quarterly, 41(4): 574-599.

Robinson, S. L., Kraatz, M. S. \& Rousseau, D. M. (1994). Changing obligations and the psychological contract: A longitudinal study. Academy of Management Journal, 37: 137-152.

Robinson, S. L. \& Morrison, E. W. (2000). The development of psychological contract breach and violation: A longitudinal study. Journal of Organizational Behavior, 21(5): 525-547.

Ross, L. (1977). The Intuitive psychologist and his shortcomings: Distortions in the attribution process. In L. Berkowitz (Ed.), Advances in Experimental Social Psychology. New York: Academic Press.

Rousseau, D. M. (1995). Psychological Contracts in organizations: Understanding written and unwritten agreements. Thousand oaks, CA: Sage.

Rousseau, D. M. \& McLean Parks, J. (1993). The contracts of individuals and organizations. In L. L. Cummings \& B. M. Staw (Eds.), Research in Organizational Behavior (Vol. 15, pp. 1-43). Greenwich, CT: JAI Press.

Rousseau, D. M. \& Wade-Benzoni, K. A. (1994). Linking strategy and human resource practices: How employee and customer contracts are created. Human Resource Management, 33(3): 463-489. 
Sitkin, S. B. \& Roth, N. L. (1993). Explaining the limited effectiveness of legalistic "remedies" for trust/distrust. Organization Science, 4: 367-392.

Thibaut, J. \& Walker, L. (1975). Procedural Justice: A Psychological Analysis. Hillsdale, NH: Lawrence Erlbaum Associates.

Tyler, T. R. \& Kramer, R. M. (1996). Whither trust? In R. M. Kramer \& T. R. Tyler (Eds.), Trust in Organizations, pp. 1-15. Thousand Oaks, CA: Sage.

Van Stormbroek, R. \& Blomme, R. (2017). Psychological contract as precursor for turnover and slef-employment. Management Research Review, 40(2): 235-250.

Verburg, R. N., Nienaber, A., Searle, R. H., Weibel, A., Den Hartog, D. N. \& Rupp, D. E. (2018). The role of organizational control systems in employees' organizational trust and performance outcomes. Group \& Organization Management, 43(2): 179-206.

Woodrow, C. \& Guest, D. (2020). Pathways through organizational socialization: A longitudinal qualitative study based on the psychological contract. Journal of Occupational and Organizational Psychology, 93(1): 110-133.

Zeffane, R. \& Bani Melhem, S. J. (2017). Trust, job satisfaction, perceived organizational performance and turnover intention. Employee Relations, 39(7): 1148-1167.

Zoghbi-Manrique-de-Lara, P. (2010). Employee deviance as a response to injustice and task-related discontent. The Psychologist-Manager Journal, 13(3): 131146.

\section{BRIEF BIOGRAPHICAL SKETCH OF AUTHOR}

Juliana D. Lilly is a Professor of Management at Sam Houston State University. She holds degrees in Hotel/Restaurant Management(B.S.), Organizational Management (M.B.A.), and Organizational Behavior (Ph.D.). She has presented research at numerous international, national, and regional academic meetings. Her publications appear in journals such as Journal of Organizational Behavior, Social Justice Research, and Current Psychology. 